\title{
Early contraceptive implants removal and its associated factors among women using implants at a National Referral Hospital, Kampala Uganda
}

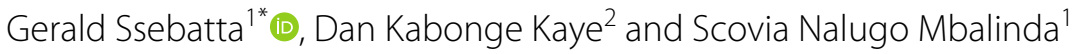

\begin{abstract}
Background: Early discontinuation of implant contraceptive methods and reasons for discontinuation remains a major concern for family planning programs. Early discontinuation is related to higher rates of the overall fertility rate, unwanted pregnancies leading to possibly induced abortion. There is paucity of data on the practice of discontinuation of contraceptives in developing countries. The objective of the study was to determine the magnitude of early implants discontinuation among women receiving implants services in the study area and the factors associated with it.

Methods: A cross-sectional study was conducted from 2nd January to 3rd March 2020. Data were collected from 207 women who had come to remove implants on socio-demographic characteristics, obstetric history, duration of implant, and reasons for wanting to remove the implant. We computed the proportion of those who removed the implant before 18 months (early discontinuation). To assess the factors associated with early discontinuation, we estimated the prevalence ratios with a generalized linear model of the poisson family with a log link and robust error variance.
\end{abstract}

Results: The proportion of early implant discontinuation was 87/207(42\%). Factor associated with early implant discontinuation included; experience of side effects ( $P R=1.1 ; 95 \% \mathrm{Cl} 1.03-1.24 ; P=0.001)$, not having received pre-insertion counseling about the benefits and side effects of contraceptive implants $(P R=1.5 ; 95 \% \mathrm{Cl} 1.02-1.30 ; P=0.019)$ and staying in rural areas (PR $=1.1 ; 95 \% \mathrm{Cl} 1.03-1.27 ; P=0.014)$.

Conclusion: Nearly one in every two mothers have early discontinuation of contraceptive implants. Factors associated with early implant removal include; experience of side effects, lack of counseling services, and staying in rural areas. There is a need for intervention to address high prevalence of early contraceptive removal through improving on counselling services about possible side effects.

Keywords: Early implant removal, Implant, Contraception

*Correspondence: ssebattagerald@gmail.com

${ }^{1}$ Department of Nursing, College of Health Sciences, Makerere University, P.O. Box 7072, Kampala, Uganda

Full list of author information is available at the end of the article

\section{Background}

According to the Uganda Demographic Health Survey, 2016, Uganda has a high fertility rate of 5.4 which is the highest in East Africa. Uganda family planning costed plan, 2014 noted a high number of unplanned pregnancies amongst rural, poor, and less educated. Also, 
a higher $32 \%$ of sexually active unmarried compared to $28 \%$ of currently married women have an unmet need for family planning. The use of implants alone is as low as $6 \%$ among married women [1]. The unmet need for contraception among married women worldwide is $10.7 \%$ [2]. More than 200 million women around the world have an unmet need for contraception [3]. Although contraception improves women's life and public health, many clients discontinue contraceptive use because of dissatisfaction related to side effects, contraceptive failure or other factors [4]. This hinders family planning 2020 aim of having an additional 120 million women and adolescents receiving family planning services by 2020 [5].

Contraceptive discontinuation is a worldwide problem that is associated with a high number of unplanned pregnancies and in a year, 182 million pregnancies across the world are unplanned that can be related to improper usage of contraceptives [6]. Implants that have been available since 1998 [7], are long-acting progestogenonly reversible contraceptive subdermal rods that act by inhibiting ovulation [8]. The method is highly effective with a failure rate of less than $1 \%$ in a year [9]. It is easy to insert and remove though requires a qualified health care provider [10]. Once the women are inserted, they require little user compliance and there is rapid return of fertility immediately after removal [8].

There are three types of contraceptive implants that include Implanon and Nexplanon, Sino-implant and Jadelle [11]. Implanon NXT is a single-rod long-acting subdermal hormonal contraceptive for 3-years of use, containing $68 \mathrm{mg}$ etonogestrel [12]. It is made of ethylene-vinyl acetate copolymer with a length of $40 \mathrm{~mm}$ and a diameter of $2 \mathrm{~mm}$ [13]. Jadelle is a set of two flexible cylindrical implants consisting of dimethylsiloxane/ methyl vinyl siloxane copolymer core enclosed in thinwalled silicone tubing [14]. Each rod contains $75 \mathrm{mg}$ of levonorgestrel and is licensed for use for 5 years [15, 16]. After the implant has been inserted there is no need for frequent visits to family planning clinics though it is associated with changes in the bleeding pattern [7].

The main consequence of early removal of implants is unwanted pregnancy that results in unsafe abortion, inadequate antenatal care, adolescent pregnancy, and socioeconomic and health disparities [17]. These unintended pregnancies are associated with high rates of mortality and morbidity among women of reproductive age [18].

The reasons for removal before the recommended time were not recorded and are unknown. Currently, Kawempe NRH provides Implanon NXT and Jadelle to women for contraception as Long Acting Reversible Contraceptive (LARC) method of family planning which are advocated for by the Ministry of health
$(\mathrm{MoH})$. There is a need to understand why women have early removal of contraceptive implants in response to achieving the Sustainable Development Goals especially Goal 3 which ensures healthy lives and promoting wellbeing for all of all ages [19]. There is limited research in Uganda and Kawempe in particular on why women have early implants removal and factors associated with it. The study findings will therefore enlighten the gaps which can be solved by health workers and stakeholders to improve clients' response to family planning services.

Efforts to increase academic attainment, effective counseling on the side effects at the time of insertion, and follow up of women will impact the continuation of implants positively [6]. Also, public enlightenment on contraceptive efficacy and safety will improve its acceptance among illiterate women [14].

\section{Methodology \\ Study setting}

The study was conducted at the family planning clinic, Kawempe NRH in Kampala Uganda. Kawempe NRH is, $4.2 \mathrm{~km}$ away from Kampala City Center. It is a government facility that provides maternal and child health services to the public including family planning services has a bed capacity of 1,500 beds According to secondary data collected from the family planning clinic at Kawempe $\mathrm{NRH}$ showed that 235 out of 625 women who were using implants between 22/10/2018 and 6/02/19 opted to discontinue but the duration of implant usage and reasons for removal were not recorded.

\section{Study design}

A facility-based cross-sectional study was conducted among women above 18-49 years who had used contraceptive implants and requested for removal at Kawempe National Referral Hospital. Data were collected for almost 2 months from 2nd-January to 4th-March 2020. Every woman was interviewed on the same day she discontinued the implant and the date on which she inserted the implant was recorded from the client card that had been given to her after insertion, this minimized recall bias.

\section{Data collection}

Data were collected once from each participant using the quantitative. Data were collected on socio-demographic (age, marital status, religion, occupation, and education), obstetric (number of children, counseling, past contraception utilization), for those who had used the implant were asked whether they had experienced side effects like menstrual disruption, acne, and arm pain etc., whether they came back to the family planning clinic after experiencing the side effects, and also asked whether they had used any modern contraceptive before. Women were 
also asked if their spouses and peers had an influence in implant usage. Data was collected on reasons to why they were removing implant that included pattern opposition, experience of side effects, peer influence and so on.

\section{Sample size determination}

The sample size was determined by using the desired precision $\mathrm{e}=0.05$ for the prevalence of early discontinuation at Kawempe NRH, a confidence level of $95 \%$ and z- statistic for the level of confidence $Z=1.96$. Using an equation developed by (Glenn, 1992) [20] for calculating the sample size in research studies, a sample size of 207 respondents was used in the study with a $100 \%$ response.

Using equation developed by (Glenn 1992) [20], $\mathbf{n}_{\mathbf{o}}=\mathbf{Z}^{2} \mathbf{p q} /$ $\mathbf{e}^{2}$, where $n_{o}$ is the sample size, $Z^{2}$ is the abscissa of the normal curve that cuts off an area alpha at tails (1-alpha equals the desired confidence level, e.g., 95\%), P is the estimated proportion of an attribute that is present in the population, $\mathrm{e}$ is the desired level of precision and $q$ is $(1-p)$. The value for $\mathrm{Z}$ is found in statistical tables that contain the area under the normal curve. Therefore, if the estimated prevalence of early implants removal, $\mathrm{p}=16 \%$ [21]. The sample size will equal to 207 women.

\section{Sampling procedure}

The family planning clinic opened at 8:00 am and closed at 5:00 pm from Monday to Friday, and all women were health educated and counselled about contraception use at 11:00 am. After counselling session, women who had come to discontinue the implant were gathered in one place in the linear order as they sat on the bench. We explained the purpose, benefits and risks of participation regarding this study and those who consented were included. Women were asked whether they had carried their implant card, and only those who had it were eligible for the study. Those who accepted were called to a private room to sign the consent form. The first participant who arrived at the health facility was selected to be the first and every the other person in the line were included in the study. Questionnaires were administered to them and after answering it fully, they proceeded to the procedure room.

\section{Inclusion criteria}

I. The study was composed of women 18 years and above who had come to discontinued implants at family planning clinic, Kawempe NRH during the study period.

II. For a respondent to be included in the study they must have been a visible record of the date of inser- tion of the contraceptive implant, either as a client card.

\section{Data collection instruments and definition of variables}

Data were collected using a semi-structured face-to-face questionnaire having three parts. The first part contained the socio-demographic characteristics (age, marital status, religion, occupation, education, pattern opposition and involvement, peer influence). The second part of the questionnaire consisted of obstetric characteristics (number of children, and abortion) while the third part consisted of method-related characteristics(side effects, follow-up, conception, counseling, past contraception utilization).

Dependent variable; Early implants removal was the dependent variable, defined as discontinuation at 18 months or less after implant insertion [22]. It was measured as a binary variable coded as 'Yes' if an implant was discontinued before 18 months from the time of insertion and 'No' if 18 or more months.

Independent variables; these included; socio-demographic factors (age, marital status, religion, occupation, and education), obstetric factors (number of children and number of induced abortion), social factors (husband perception and peer group influence) and method related factors (type and duration of usage, side effects, follow up, conception, counseling, past contraception utilization).

\section{Data collection procedure}

Participants were recruited at the family planning clinic, Kawempe NRH, every Monday to Friday, between 8.00 am and $4.00 \mathrm{pm}$.

There was one research assistant who was trained for one day before data collection on the contents of the study, contents of the questionnaires, and interview skills.

\section{Data analysis and management}

The raw data from the filled questionnaires were entered into Statistical Package for Social Services (SPSS), cleaned, coded. Descriptive statistics including proportion, percentage, mean, median, and standard deviation were presented in text and tables. Results of Bivariate and multivariate analysis are presented in table. To assess the factors associated with early implant removal, we estimated the prevalence ratios (RR) with a generalized linear model of the poisson family with a log link and robust error variance.

The significance level was set at 5\% for all tests of significance. 


\section{Results}

Table 1 shows the socio-demographic characteristics of the respondents. Most participants 140/207 (67.6\%) were aged 25 years and above, 128/207 (61.8\%) had attained secondary level or above, 158/207 (76.3\%) were married, 82/207 (39.6\%) were Catholics, while $153 / 207$ (73.9\%) stayed in urban area. The participants were also asked about occupation majority, 87 (42.0\%) were housewives, 60 (29.0\%) were employed, 56(27.1\%) were traders and majority of their spouses $92(44.5 \%)$ were traders (Table 1 ).

\section{Obstetrics related characteristics}

The majority of participants $121 / 207(58.5 \%)$ had at least $1-2$ children while $13 / 207$ (6.3\%) had more than five alive children. Participants were also asked if they had ever had an abortion, 69/207 (33.3\%) had ever had an abortion but the majority had ever had it once 52/69 (75.4\%). One hundred sixty-five (79.7\%) had a desire for more children in the future, out of those who had a future desire to have children 95/165 (57.6\%) wanted to have babies after 2 years while 56/165 (33.9\%) wanted to have babies in less than one year (Table 1).

Table 1 also shows results of method related characteristics and majority of the participants 135/207 (65.2\%) had ever used modern contraceptives before the currently discontinued implant, out of those who had used modern contraceptives before 85/135 (63.0\%) were using injectable followed by oral contraceptive pills 20/135 (14.8\%). Most participants 145/207 (70.0\%) were using Implanon NXT while 62/207 (30.0\%) were using Jadelle. All the participants were asked whether they received counselling about the implants in terms of efficacy and side effects, whereby 170/207 (82.1\%) reported that they were counseled. Then further asked whether after insertion of implants they were given future appointment dates, 117/207 (56.5\%) of the study participants did not have appointments follow-up during their implant utilization period (Table 1).

The proportion of early discontinuation of implants was $87 / 207$ (42.0\%). All of the women who removed the implants due to the desire to conceive 63/207 (30.4\%), and those who switched to another method 12/207 (5.8\%) discontinued before 18 months. For compensation of early implant removal, one would prefer women to discontinue and switch or to discontinue in order to conceive. Therefore, a target proportion can be determined by ((sum of (women who discontinue early and switch $=12$ plus women who discontinue early to conceive $=63$ ) $/$ by total of women who discontinue early $=87)$ ) of 0.42 equivalent to $36.2 \%$ (Table 2 ).

The major reason for early removal of implants was due to side effects that accounted for 174/207 (84.1\%) that included 139/174 (54.5\%) for menstrual disruption, 56/174 (20.4\%) for headache, weight body changes 43/174 (15.6\%), insertion site pain 21/174 (7.64\%), acne and pruritus 9/174 (3.3\%), and loss of sexual desire $7 / 174$ (2.6\%) (Table 3). These were followed by $63 / 207$ (30.4\%) those participants who had the plan to conceive shortly, 42/207 (20.3\%) had been influenced by their partners to discontinue, 6/207 (2.9\%) claimed that they had conceived while using implant but one participant was interviewed and was found to be pregnant before implant insertion (Table 4).

\section{Factors associated with early implants removal among women using implants at NRH}

The early discontinuation rate of implants was $87 / 207$ (42\%) using a cut-off of 18 months. Table 5 shows factors associated with early contraceptive implant discontinuation. No variable was excluded from analysis for the association because each category had desired frequencies when checked by cross-tabulation.

The results showed that women who had experienced side effects discontinued the implant early $(\mathrm{PR}=1.13$; 95\% CI 1.02-1.24, $P=0.010$ ). Women who had not been counseled removed implant early $(\mathrm{PR}=1.5 ; 95 \%$ CI 1.02-1.304, $P=0.019)$. Women who resided in rural areas removed implant early $(P R=1.1 ; 95 \%$ CI $1.03-1.27$, $P=0.014$ ) (Table 5).

\section{Discussion}

The study established the factors associated with early implant removal among women at a National Referral Hospital aged 18-49 years. The proportion of early implant removal was high, and factors associated with it were the experience of side effects, lack of effective counseling before insertion, and staying in rural areas.

\section{Proportion of early discontinuation of implants}

This facility-based study assessed for early discontinuation of implants (Implanon and Jadelle) among women who were using implants at Kawempe NRH, Kampala district. The prevalence of early discontinuation of implants in this study is similar to that of a study done in Sudan which found a discontinuation rate of $43 \%$ [23]. However, the current proportion is higher than other studies conducted as in Ethiopia 16\% [21] and 23.4\% [8]. Other studies done in Ethiopia had a discontinuation rate higher than the current study. In a study conducted in Debre Tabor Town, Northwest Ethiopia, early discontinuation was at $65 \%$ [6]. The difference could be attributed to the improved effort of pre-insertion counseling particularly about the possible side effects of the method as compared to the previous study. In the previous study 
Table 1 Social-demographic, obstetric history, contraceptive related characteristics of implants users at National Referral Hospital, Kampala Uganda $(n=207)$

\begin{tabular}{|c|c|c|}
\hline Variable & Frequency & Percentage (\%) \\
\hline \multicolumn{3}{|l|}{ Social-demographic } \\
\hline \multicolumn{3}{|l|}{ Woman's age } \\
\hline $18-24$ & 67 & 32.4 \\
\hline 25 and above & 140 & 67.6 \\
\hline \multicolumn{3}{|l|}{ Marital status } \\
\hline Divorced & 5 & 2.4 \\
\hline Cohabiting & 16 & 7.7 \\
\hline Widowed & 3 & 1.4 \\
\hline Married & 158 & 76.3 \\
\hline Single & 25 & 12.1 \\
\hline \multicolumn{3}{|l|}{ Religion } \\
\hline Catholic & 82 & 39.6 \\
\hline Born again & 54 & 26.1 \\
\hline Protestant & 46 & 22.2 \\
\hline Muslim & 19 & 9.2 \\
\hline Jehova & 6 & 2.9 \\
\hline \multicolumn{3}{|l|}{ Address } \\
\hline Urban & 153 & 73.9 \\
\hline Rural & 54 & 26.1 \\
\hline \multicolumn{3}{|l|}{ Level of education } \\
\hline Below secondary & 79 & 38.2 \\
\hline Secondary and above & 128 & 61.8 \\
\hline \multicolumn{3}{|l|}{ Women's occupation } \\
\hline Housewife & 87 & 42.0 \\
\hline Employee & 60 & 29.0 \\
\hline Trader & 56 & 27.1 \\
\hline Student & 4 & 1.9 \\
\hline \multicolumn{3}{|l|}{ Obstetric history } \\
\hline \multicolumn{3}{|l|}{ Number of living children } \\
\hline $0-2$ & 130 & 62.8 \\
\hline $3+$ & 77 & 37.2 \\
\hline \multicolumn{3}{|l|}{ History of abortion } \\
\hline Yes & 69 & 33.3 \\
\hline No & 138 & 66.7 \\
\hline \multicolumn{3}{|c|}{ The desire for more children in the future } \\
\hline Yes & 165 & 79.7 \\
\hline No & 42 & 20.3 \\
\hline \multicolumn{3}{|c|}{ Ever used modern contraceptive before insertion of Implants } \\
\hline Yes & 135 & 65.2 \\
\hline No & 72 & 34.8 \\
\hline \multicolumn{3}{|c|}{ Type of contraceptive used before insertion of Implants $(n=135)$} \\
\hline Injectable & 85 & 63.0 \\
\hline Condoms, IUCD, OCP & 50 & 37.0 \\
\hline \multicolumn{3}{|l|}{ Type of implant used } \\
\hline Implanon NXT & 145 & 70.0 \\
\hline Jadelle & 62 & 30.0 \\
\hline \multicolumn{3}{|l|}{ Experience of side effects } \\
\hline Yes & 174 & 84.1 \\
\hline
\end{tabular}


Table 1 (continued)

\begin{tabular}{lcc}
\hline Variable & Frequency & Percentage (\%) \\
\hline No & 33 & 15.9 \\
Counseling about efficacy and side effects & 170 & 82.1 \\
Yes & 37 & 17.9 \\
No & & 90 \\
Had follow-up appointments & 117 & 43.5 \\
Yes & & 56.5 \\
No & & \\
\hline
\end{tabular}

Table 2 Proportion of women of reproductive age 15-49 years who discontinued implants early at a National Referral Hospital $(n=207)$

\begin{tabular}{|c|c|c|}
\hline Variable & Frequency & Percentage (\%) \\
\hline \multicolumn{3}{|c|}{ Early discontinuation of implants $(n=207)$} \\
\hline Yes & 87 & 42.0 \\
\hline No & 120 & 58.0 \\
\hline \multicolumn{3}{|c|}{ Early discontinuation of implanon NXT $(n=145)$} \\
\hline Yes & 64 & 44.1 \\
\hline No & 81 & 55.9 \\
\hline \multicolumn{3}{|c|}{ Early discontinuation of Jadelle $(n=62)$} \\
\hline Yes & 23 & 37.1 \\
\hline No & 39 & 62.9 \\
\hline Min. duration of use (1 month) & 9 & 4.3 \\
\hline Min. duration of use (60 months) & 8 & 3.9 \\
\hline Median duration of use & 19 & \\
\hline \multicolumn{3}{|c|}{ Early removal due to desire to conceive $(n=63)$} \\
\hline Yes & 63 & 100 \\
\hline No & 0 & 0 \\
\hline \multicolumn{3}{|c|}{ Early removal due to switching to another method $(n=12)$} \\
\hline Yes & 12 & 100 \\
\hline No & 0 & 0 \\
\hline
\end{tabular}

Table 3 The main side effects of Implant for early discontinuation among women using implants at Kawempe $\mathrm{NRH}(\mathrm{n}=174)$

\begin{tabular}{lcl}
\hline Side effects & Frequency & Percentage (\%) \\
\hline Menstrual disruption & 139 & 50.54 \\
Headache & 56 & 20.36 \\
Weight gain/loss & 43 & 15.64 \\
Arm pain/insertion site pain & 21 & 7.64 \\
Acne and pruritus & 9 & 3.27 \\
Loss of sexual desires & 7 & 2.55 \\
Total & 275 & 100
\end{tabular}

NB: Most of the women reported more than one side effects
Table 4 Reasons for removal of the contraceptive implant at National Referral Hospital, Kampala Uganda $(n=207)$

\begin{tabular}{lcl}
\hline Reasons for removal & Frequency & Percentage (\%) \\
\hline Desire for pregnancy & 63 & 16.9 \\
Partner influence & 42 & 11.3 \\
Husband's death & 4 & 1.1 \\
Switch to another method & 12 & 3.2 \\
Divorce & 5 & 1.3 \\
Side effects & 174 & 46.6 \\
Traveling abroad & 18 & 4.8 \\
Conception & 6 & 1.6 \\
Expiry & 49 & 13.1 \\
Total & 373 & 100 \\
\hline
\end{tabular}

NB: Women gave more than one reason for discontinuation of implant 
Table 5 Factors associated with early implants removal among women using implants at $\mathrm{NRH}(n=207)$

\begin{tabular}{|c|c|c|c|c|}
\hline Variables & PR (95\% Cl) & $P$-value & A. PR $(95 \% \mathrm{Cl})$ & $P$-value \\
\hline \multicolumn{5}{|c|}{ Age of participants } \\
\hline $18-29$ & $1.076(0.987-1.173)$ & 0.097 & $1.079(0.995-1.170)$ & 0.066 \\
\hline$>29$ & 1 & & & \\
\hline \multicolumn{5}{|c|}{ Counseling about benefits and side effects } \\
\hline Yes & 1 & & 1 & \\
\hline No & $1.51(1.02-1.3)$ & $0.023^{*}$ & $1.54(1.02-1.30)$ & $0.019^{*}$ \\
\hline \multicolumn{5}{|c|}{ Abortion history } \\
\hline Yes & 1 & & 1 & \\
\hline No & $1.1(0.98-1.17)$ & 0.125 & $1.04(0.95-1.13)$ & 0.422 \\
\hline \multicolumn{5}{|c|}{ Removal due to side effects } \\
\hline Yes & $1.137(1.033-1.252)$ & $0.009^{*}$ & $1.131(1.023-1.242)$ & \\
\hline No & 1 & & 1 & $0.010^{*}$ \\
\hline \multicolumn{5}{|c|}{ Address of participants } \\
\hline Urban & 1 & & 1 & \\
\hline Rural & $1.15(1.033-1.271)$ & $0.010^{*}$ & $1.14(1.03-1.27)$ & $0.014^{*}$ \\
\hline
\end{tabular}

NB: ${ }^{*} P<0.05$ : significant variables; $P R$ prevalence ratio, $A . P R$ adjusted prevalence ratio

in Debre Tabor Town, $31.8 \%$ were counseled about the possible side effects compared to the current study were $82.1 \%$ were counseled [6]. Also, more than half in the current study had ever used any other modern contraceptive method before, this increases the chance of a continuation of implants since participants might have familiarized themselves with side effects of contraceptive methods [24].

Different studies show variations in discontinuation rates. This could be attributed to different cut off for early discontinuation whereby in Ethiopia 2.5 years was used as cut off for early implant removal [6], while a cut of 18 months was used in Uganda [22]. In other studies, the low discontinuation rates were attributed to effective pre-insertion counselling about possible side effects. For instance, in a study conducted in Mekelle City 34 percent of the women who were counselled discontinued early while in the current study 38.2 percent discontinued early of the women who were counselled [23]. In Uganda, there is a study that assessed early discontinuation of both contraceptive implants with an early discontinuation rate was $31 \%$ in the facility-based cross-sectional study conducted in the Wakiso District. This was lower compared to the current study and the difference could be attributed to the denominator for assessing the proportion whereby the current study only included age of 18 years and above while the study done in Wakiso district included women of reproductive age 15-49 years from 42 health facilities in a rural and urban setting [22]. The other reason for the difference could be attributed to a cost incurred to retain the implant where $27.2 \%$ of women incurred a cost in the previous study conducted in Wakiso district compared to the current study where services rendered to women were for free of charge, this would be a barrier from seeking health care whenever they experience side effects.

Pre-insertion counselling in family planning helps women and their partners to gain increased control over their reproductive health. Providing counseling during the insertion of Implants was positively associated with the continuation of use [8]. Preplacement counseling about the possible side effects of the method and support by the service providers might be the most important way to help women continue on Implants contraception [25]. Women and couples who receive better counseling on their method may be more aware of potential side effects and how to cope with them. In this study, the women who were not counselled were more likely to have early implant removal. This is consistent with the study findings conducted in Debre Tabor Town, Northwest Ethiopia [6]. This is because when the women are informed about the possible side effect of the method, they will tolerate side effects but those who were not informed will seek the removal of the method. Timely follow up and appropriate counseling helps the women to cope with side effects which ultimately prevents discontinuation. The acceptance and awareness of any contraceptive implants will be increased through involving the couple during counseling sessions [26].

The occurrence of side effects has a negative impact on whether a woman continues to use family planning. In this study women who experienced side effects were more likely to have early implant removal. This is consistent with the study conducted in Tigray [21] and Debre Tabor Town [6] were women who experienced a side effect of the method led to early Implant discontinuation. In addition to this, respondents may fear different complication as a result of side effects, this may lead to discontinuation of implant early. The main reasons for the removal of the implant in this current study were side effects, followed by a desire for more children, expiry, partner influence, and conception. Among the side effects, menstrual disruption and headaches were most common. This is consistent with other studies conducted in Ethiopia [21]. Menstrual disruption has no serious effects on health but can interfere with daily activities, especially sexual relationships and possibly with work [21]. Women who requested implant removal due to side effects would have received misleading information from non-professional persons in the community, lacked appropriate counseling about side effects and appointment dates for follow-up. This means that immediate action upon the management of bleeding problems will enable the continuation of the contraceptive implant. 
One of the reasons for early implant removal was pressure from spouses. Men need to understand their role in reproduction so that they can share the responsibility for family planning and birth spacing. In this study partner disapproval of the contraceptive implant was among the reasons for the discontinuation and accounted for a fifth of early implant removal. Male involvement in maternal health contributes a lot to the reduction of mortality and improvement of maternal health as well as family health [9]. This suggests that to enable the continuation of implants, males should be involved in counseling sessions concerning contraception, before and during the period of implant use.

Residence appeared to be one factor associated with early removal of implants. Women in urban areas may be of better socioeconomic status, easy access to family planning services, cultural disparity, and high level of female literacy as compared to women in rural areas. This study showed that women who live in urban areas were less likely to discontinue implants early compared to those who live in rural areas. The difference can be attributed to occupation status. It is possible that women who live in rural areas are housewives and may discontinue implants early to have more children compared to their counterparts in urban areas who work in different jobs. This is in line with a study conducted in Dale District, Southern Ethiopia where women with high monthly income were less likely to discontinue the method [8]. Women in urban areas might have attained a higher level of education who often seek early healthcare whenever there is any disturbance from normal physiology [27] this increased number of encounter with health workers promotes confidence among women. Also, women who have attained a higher level of education can get more information from different reliable sources about contraceptive implants [23].

\section{Limitation}

Being a cross-sectional study that was conducted from a health facility, it was not easy to determine the impact of early discontinuation of implants. Though the data collector was a midwife and well trained before data collection, she was a staff at that health facility, so the interview's bias would not be excluded from this study.

\section{Conclusions}

In this study discontinuation of implants was high as nearly one of every 2 women had early removal of the implant. Experience of side effects, counseling services, and staying in rural areas were factors associated with early discontinuation. Quality family planning services that involve males during counseling sessions on the benefits and side effects are a vital way through which early implants discontinuation can be minimized.

\section{Abbreviations}

Cl: Confidence interval; IUCD: Intrauterine contraceptive device; LARC: Long acting reversible contraceptive; $\mathrm{MoH}$ : Ministry of health; $\mathrm{NRH}$ : National Referral Hospital; OR: Odds ratio; OCP: Oral contraceptive pills; UBOS: Uganda Bureau of Statistics; UDHS: Uganda Demographic Health Survey.

\section{Acknowledgements}

Special thanks go to participants, and staff at the family planning clinic for the support in terms of knowledge and time you rendered to me. The author's gratitude goes to colleagues, data collectors, study participants, and friends indeed Namayengo Rebecca, Derrick AmootiLusota, Nantuwa Agnes who supported me in the process of report development.

\section{Authors' contributions}

GS, KKD, SNM, Conceptualized and designed the study, developed the methodology, supervised the data collection, analyzed and interpreted the data and wrote the manuscript. All authors read and approved the final manuscript.

\section{Funding}

I appreciate the financial support provided by the 'Fogarty International Center of the National Institutes of Health, U.S. Department of State's Office of the U.S. Global AIDS Coordinator and Health Diplomacy (S/GAC), and President's Emergency Plan for AIDS Relief (PEPFAR) under Award Number 1R25TW011213. This content is solely the responsibility of the authors and does not necessarily represent the official views of the National Institutes of Health.'

\section{Availability of data and materials}

The datasets used and/or analyzed during the current study are available from the corresponding author on reasonable request.

\section{Declarations}

\section{Ethics approval and consent to participants}

The study sought approval and abided by the rules and regulations of the institutional review board of Makerere University School of Health Sciences Research and Ethics Committee, SHSREC REF NO: 2019-071. Permission to conduct the study was also grantedby Kawempe NRH administration. All methods were performed in accordance with the relevant guidelines and regulations. The participants were requested to participate in the study voluntarily. All participants provided consent by signing the informed consent form. The purpose and benefits were clearly explained to participants, ensuring privacy and confidentiality.

\section{Consent for publication}

Not applicable.

\section{Competing interests}

The authors declare that they have no competing interests.

\section{Author details}

${ }^{1}$ Department of Nursing, College of Health Sciences, Makerere University, P.O. Box 7072, Kampala, Uganda. ${ }^{2}$ Department of Obstetrics and Gynecology, College of Health Sciences, Makerere University, P.O. Box 7072, Kampala, Uganda.

Received: 5 January 2021 Accepted: 12 November 2021

Published online: 01 December 2021

\section{References}

1. UBOS, ICF. Uganda demographic and health survey 2016. Rockville: UBOS; 2017.

2. Bahamondes L, Brache V, Meirik O, Ali M, Habib N, Landoulsi S, et al. A 3-year multicentre randomized controlled trial of etonogestrel-and levonorgestrel-releasing contraceptive implants, with non-randomized matched copper-intrauterine device controls. Hum Reprod. 2015:30:2527-38. https://doi.org/10.1093/humrep/dev221.

3. Callahan RL, Brunie A, Mackenzie AC, Wayack-Pambè M, Guiella G, Kibira SP, et al. Potential user interest in new long-acting contraceptives: Results 
from a mixed methods study in Burkina Faso and Uganda. PLOS ONE. 2019;14:e0217333. https://doi.org/10.1371/journal.pone.0217.

4. Sanders NJ, Jenny AH, Daniel EA, Greggory JS, Lori MG. The impact of sexual satisfaction, functioning, and perceived contraceptive effects on IUD and Implant Continuation at 1 year. Womens Health Issues. 2018;28:401-7. https://doi.org/10.1016/j.whi.2018.06.003.

5. FP2020. What is family planning 2020 factsheet updated v1. [Online] 2015. Cited 10 May 2021. www.fammilyplanning2020.org.

6. Melkamu Asaye M, Syoum Nigussie T, Mequannt Ambaw W. Early implanon discontinuation and associated factors among implanon user women in Debre Tabor Town, public health facilities, Northwest Ethiopia, 2016. Int J Reprod Med. 2018. https://doi.org/10.1155/2018/3597487.

7. Khungelwa PM, Daniel TG, Eyitayo OO, Oladele V, Eunice S, Anthony IA. Reasons for discountinuation of implanon among users in Buffalo City Metropolitan Municipality, South Africa: a cross-sectional study. Afr J Reprod Health. 2018. https://doi.org/10.29063/ajrh2018/v22i1.11.

8. Nageso A, Achamyelesh G. Discontinuation rate of implanon and its associated factors among women who ever used Implanon in Dale District, Southern Ethiopia. BMC Women's Health. 2018. https://doi.org/10.11186/ s12905-018-0678-x.

9. Adeagbo AO, Mullick S, Pillay D, Chersich MF, MOrroni C, Naidoo N, et al. Uptake and early removals of implanon NXT in South Africa: Perceptions and attitudes of healthcare workers. SAMJ. 2017. https://doi.org/10.7196/ SAMJ.2017.v107i10.12821.

10. Gbolade BA. Attempted self-removal of Implanon: a case report. Asian Pac J Reprod. 2015. https://doi.org/10.1016/j.apjr.2015.06.011.

11. WHO. Statement on progestogen-only implants. World Health Organisation Department of Reproductive Health and Research. [Online] 2016. Cited 10 May 2021. www.who.int/reproductivehealth.

12. Park JU, Bae HS, Lee SM, Bae J, Park JW. Removal of a subdermal contraceptive implant (Implanon NXT) that migrated to the axilla by C-arm guidance: a case report and review of the literature. Medicine. 2017. https://doi.org/10.1097/MD.00000000000008627.

13. Singh S, Gupta S, Nigam N, Nigam SK. A study of efficacy and safety profile with sub dermal single rod contraceptive implant. J Evol Med Dent Sci. 2015;4:3765-74. https://doi.org/10.14260/jemds/2015/543.

14. Muhammad Z, Ibrahim SA, Attah RA. Jadelle subdermal contraceptive implant in Aminu Kano teaching hospital Kano, northern Nigeria. Trop J Obstet Gynaecol. 2016;33:86-90.

15. Oranu EO, Ojule JD. A decade of jadelle subdermal implant contraception in a tertiary health institution in Port Harcourt, Southern Nigeria. J Biosci Med. 2018;6:123. https://doi.org/10.4236/jbm.2018.63010.

16. Roke C, Roberts $H$, Whitehead A. New Zealand women's experience during their first year of Jadelle ${ }^{\circledR}$ contraceptive implant. J Prim Health Care. 2016:8:13-9. https://doi.org/10.1071/HC15040 (PMID:27477370).
17. Bahamondes L, Brache V, Meirik O, Ali M, Habib N, Landoulsi S. A 3-year multicentre randomised controlled trial of etonogestrel-and levonorgestrel contraceptive implants, with non-randomized matched copperintrauterine device controls. Hum Reprod. 2015. https://doi.org/10.1093/ humrep/dev221.

18. Nalwadda G, Mirembe F, Byamugisha J, Faxelid E. Persistent high fertility in Uganda: young people recount obstacles and enabling factors to use of contraceptives. BMC Public Health. 2010;10:1-3. https://doi.org/10. 1186/1471-2458-10-530.

19. Dockalova B, Katie L, Heather B, Alison M. Sustainable development goals and family planning 2020. IPPF. https://www.ippf.org.

20. Glenn DI (1992) Determining Sample Size. University of Florida IFAS EXTERSION. https://www.academia.edu.

21. Birhane K, Hagos S, Fantahun M. Early discontinuation of implanon and its associated factors among women who ever used implanon in Ofla District, Tigray, Northern Ethiopia. Int J Pharma Sci Res. 2015;6:544-51.

22. Ddungu U. Factors asssociated with early discontinuation of contraceptive implants among women of reproductive age in Wakiso District, a facility based cross-sectional study. Dspacemakacug. 2019. http://hdl. handle.net/10570/7629.

23. Gebrekidan KG, Nerea MK, Gerezgiher H, Haftu M. Early Implanon discontinuation rate and its associated factors in health institutions of Mekelle City, Tigray, Ethiopia 2016/17. BMC Res Notes. 2019;12:1-6. https://doi. org/10.1186/s.13104-018-3992-3.

24. Determinants of Discontinuation of Contraceptive Methods among Women at Kenyatta National Hospital, Kenya. 2016. http://journals.uonbi. ac.ke/ajpt.

25. Romano ME, Braun-Courville DK. Assessing weight status in adolescent and young adult users of the etonogestrel contraceptive implant. J Pediatr Adolesc Gynecol. 2019;32:409-14. https://doi.org/10.1016/j.jpag.2019. 03.008.Epub2019Mar27.PMID:30928532.PubMed.

26. El-Khoury M, Thornton R, Chatterji M, Kamhawi S, Sloane P, Halassa M. Counseling women and couples on family planning: a randomized study in Jordan. Stud Fam Plan. 2016;47:222-38. https://doi.org/10.1111/sifp.69.

27. Mamo K, Desta MS. Premature Implanon discontinuation and associated factors among implanon user women in Ambo town, Central Ethiopia. J Health Med Nurs. 2018. https://doi.org/10.7176/JHMN/58.05.

\section{Publisher's Note}

Springer Nature remains neutral with regard to jurisdictional claims in published maps and institutional affiliations.
Ready to submit your research? Choose BMC and benefit from:

- fast, convenient online submission

- thorough peer review by experienced researchers in your field

- rapid publication on acceptance

- support for research data, including large and complex data types

- gold Open Access which fosters wider collaboration and increased citations

- maximum visibility for your research: over 100M website views per year

At BMC, research is always in progress.

Learn more biomedcentral.com/submissions 